\title{
TEXTURAS GOETHEANAS EN EL JOVEN NIETZSCHE: APUNTES SOBRE LAS FUNCIONES DEL FAUSTO EN EL NACIMIENTO DE LA TRAGEDIA
}

Goethean textures in Young Nietzsche: notes on Faust and its functions in The Birth of Tragedy

\author{
Kilian Lavernia Biescas \\ UNED-Madrid
}

\begin{abstract}
RESUMEN: Una de las tareas pendientes más fascinantes que los estudios nietzscheanos tienen todavía por delante es la reconstrucción hermenéutica de la influencia de Goethe en la obra de juventud del filósofo alemán. Partiendo en primer lugar de tres dimensiones goetheanas como son su reflexión científica, su meditación sobre la Bildung y la Kultur, el artículo estudiará seguidamente las posibles funciones y significados del Fausto en $E l$ nacimiento de la tragedia. Puesto que en la opera prima de Nietzsche encontramos una compleja apropiación y reelaboración creativas de numerosos temas, motivos y lugares comunes de la gran obra goetheana, una cuidadosa lectura intertextual de algunos capítulos permitirá visibilizar hasta qué punto los versos del Fausto sirven también para refrendar algunas hipótesis centrales de la obra nietzscheana.
\end{abstract}

Palabras clave: joven Nietzsche - Goethe - Fausto - cultura

ABSTRACT: The hermeneutical reconstruction of Goethe's influence in Nietzsche's early works is still one of the most fascinating tasks to be undertaken by the Nietzschean studies. For this aim, we will, firstly, propose three Goethean dimensions of analisis, as scientist, as a thinker of Bildung and Kultur, in order to shape, secondly, the possible functions and meanings of Faust in Nietzsche's The Birth of Tragedy. For his opera prima deals with a creative appropiation and reelaboration of numerous themes, motifs and common places of the great Goethean play, an intertextual reading of some concrete chapters will strenghten the idea that Faustian poetry reaffirms some central hypothesis of Nietzsche's early work.

Keywords: Young Nietzsche - Goethe - Faust - Culture

El siguiente estudio se propone abordar una determinada lectura de El nacimiento de la tragedia desde algunos de los numerosos temas, motivos y lugares comunes que el joven Nietzsche extrajo del Fausto goetheano ${ }^{1}$. Ahora bien, puesto que una reconstrucción hermenéutica de esta naturaleza no puede entenderse sin una debida orientación previa con respecto a la relación del joven Nietzsche con la figura del genio weimarés, resulta imperativo desarrollar, en una primera parada, algunas de las líneas de fuerza que dan unidad y sentido a dicha relación.

1. Su origen se encuentra en una conferencia pronunciada en el Goethe-Institut de Madrid en noviembre de 2015, a invitación del Seminario Nietzsche Complutense en el marco del ciclo «Nietzsche: filosofía en el marco de la cultura occidental». 
Expuestas estas coordenadas daremos paso, en segundo lugar, al comentario de algunos pasajes seleccionados de la opera prima nietzscheana. En ellos, podremos valorar hasta qué punto Nietzsche integra y reinterpreta creativamente el potente imaginario textual de la gran obra goetheana y, de forma particular, en qué medida las texturas de lo fáustico le sirven también para refrendar el horizonte filosófico de su temprana crítica a cultura moderna.

¿Cómo debemos entender el diálogo que el joven Nietzsche mantendrá con Goethe? ¿Cómo podemos estructurarlo, aun cuando sea en términos ideales? Sobre este punto podríamos estar inclinados a recurrir a ese inconfundible lugar común - aplicable no tanto al joven Nietzsche, sino al conjunto de su obra- según el cual la centralidad de Goethe se debería medir por el simple hecho de haber sido uno de los pocos caminos del pensar nietzscheanos donde no hubo rupturas, como con Wagner, o un distanciamiento crítico, como con Schopenhauer, sino en el que se puede aventurar la hipótesis de una continuidad y afinidad espirituales en el tiempo. Por tanto, siguiendo esta productiva línea de investigación ${ }^{2}$, no estaríamos hablando de una influencia menor, ni de una lectura pasajera que Nietzsche realizó con motivo de algún interés filosófico, literario o científico específicos. Antes bien, Goethe será, entre otras muchas cualidades señaladas por el propio Nietzsche maduro $^{3}$, el único personaje destacado de la cultura alemana que se salve de su duro juicio sumarísimo: un nombre cuya ejemplaridad jamás será negada, un modelo de escritor, pensador, científico y espíritu libre alemán verdaderamente europeo e intempestivo - desde luego un «buen europeo»—, un artista del «gran estilo», un noble poeta-filólogo, en suma, un individuo independiente y excepcional dotado de una voluntad de poder fuerte y creativa.

Ahora bien, mientras que esta valoración sobre la imagen de Goethe en la obra nietzscheana sin duda se aplica a la época de madurez, en lo que se refiere a la época de juventud aquí considerada - mucho menos estudiada que la prime$\mathrm{ra}^{4}-$, me parece fundamental aprender a distinguir, al menos desde un punto de

2. Sin duda la tendencia más consolidada en la Nietzsche-Forschung, en la cual se estudia la innegable presencia y magisterio espirituales de Goethe en el Nietzsche maduro. Cf. recientemente D. Sánchez Meca en el capítulo «De Goethe a Nietzsche: clasicismo, romanticismo, dionisismo", en ibid., El nibilismo. Perspectivas sobre la historia espiritual de Europa, Madrid: Síntesis, 2004, pp. 4962; también K. Pestallozzi, «'Hier ist die Aussicht frei, der Geist erhoben'. Nietzsche liest Goethe»: Nietzsche-Studien 41 (2012), 17-42, o también V. Gerhardt, «Nietzsche, Goethe und die Humanität», en ibid., Die Funken des freien Geistes. Neuere Aufsätze zu Nietzsches Philosophie der Zukunft, Berlin/ New York: Walter de Gruyter, 2011, pp. 305-320.

3. A título de ejemplo, cf. MA I, 170; MA II, 2. a , 125; FW, 103; WA, 3; GD, «Incursiones de un intempestivo", 49-51.

4. Notables excepciones son los trabajos corales de P. Bishop y R. H. Stephenson, Friedrich Nietzsche and Weimar Classicism, New York: Camden House, 2005, pp. 1-62, que tienen su origen en ibid., «Nietzsche and Weimar Aesthetics», en German Life and Letters 52 (1999), pp. 412-429. Cf. también S. Barbera, «Dal mito alla tradizione. Il Goethe di Nietzsche», en su obra póstuma Guarigioni, rinascite e metamorfosi. Studi su Goethe, Schopenhauer e Nietzsche, Florencia: Le Lettere, 2010, pp. 135-160. Por otro lado, sobre Goethe en la niñez y adolescencia de Nietzsche, cf. «Verklärt-reine 
vista heurístico, tres dimensiones o vertientes de lo goetheano. Su reconstrucción ideal, en cierto modo tipológica, resulta indispensable para facilitar la viabilidad hermenéutica de nuestra propuesta de lectura, en la medida en que dichas vertientes reaparecerán, aunque codificadas literariamente, en la compleja apropiación y reelaboración creativas de numerosos motivos y temas del Fausto entretejidos en El nacimiento de la tragedia.

\section{Goethe cientifico}

En su época universitaria en Leipzig, el joven Nietzsche se interesará por la original aproximación científica de Goethe con respecto al conocimiento de la naturaleza, sobre todo aquella que se desprendía de las investigaciones de su Morfología de las plantas $^{5}$. Para ello resulta imprescindible estudiar con detenimiento la inacabada tesis doctoral titulada «La teleología a partir de Kant» (OC I, 304-320), donde el doctorando ensaya una crítica radical a la finalidad de la naturaleza desde el intento de mostrarla como pura construcción antropomórfica ${ }^{6}$. Frente a la afirmación kantiana del organismo como unidad teleológica, en la que distintas partes actúan unas sobre otras de acuerdo con un diseño previo, Goethe había desarrollado un concepto de naturaleza como no-sistema, como pluralidad sin orden ni desorden, como vida y sucesión desde un centro desconocido hacia un confín incognoscible: «Todo ser vivo», recogerá de él Nietzsche, «no es un individuo, sino una pluralidad: incluso cuando se nos muestra como individuo sigue siendo una reunión de seres vivos independientes» (OC I, 308). Es decir, frente a la idea de una naturaleza explicada a partir de las causas finales, la negativa goetheana a separar kantianamente idealidad y materialidad había optado por una profundización de la concepción spinozista de la naturaleza como unidad de materia y espíritu, si bien adaptando su horizonte a una comprensión dinámica de transformación o metamorfosis continuas de la materia en la forma, como fuerza inmanente a la forma ${ }^{7}$. La concentración goetheana en la forma garantizaba la persistencia tem-

Herbstlichkeit. Einige Anmerkungen zu Nietzsches erster Bekanntschaft mit Goethe», en CentaurenGeburten. Wissenschaft, Kunst und Philosophie beim jungen Nietzsche, T. Borsche et al. (eds.), Berlin/ New York: Walter de Gruyter, 1994, pp. 257-267.

5. Cf. J. W. Goethe, Teoría de la naturaleza, ed. y trad. de D. Sánchez Meca, Madrid: Tecnos, ${ }^{2} 2007$.

6. Sobre la importancia filosófica de esta época universitaria, me remito a mi reciente artículo "Cuerpo y verdad en el joven Nietzsche: apuntes sobre la problemática gnoseológica en Sobre verdad y mentira en sentido extramoral»: Éndoxa 39 (2017) [en prensa].

7. Cf., sobre este tema, D. Sánchez Meca, «Los conceptos griegos de physis y theoria en la interpretación de Goethe»: Daimon. Revista de Filosofía 16 (1998), pp. 57-71. Sobre el pensamiento morfológico de Goethe en general y sus distintas recepciones, cf. las recientes contribuciones en J. Maatsch (ed.), Morphologie und Moderne Goethes «anschauliches Denken» in den Geistes- und Kulturwissenschaften seit 1800, Berlin/New York: Walter de Gruyter, 2014. Por otro lado, «la incompatibilidad de Goethe respecto de Kant debe ser encuadrada en un nivel más amplio que en el de la mera negación crítica de la teleología metafísica. Su lugar se encuentra, sin duda, en la decisión kantiana de situar en las estructuras trascendentales del yo el origen del significado de lo real, pues con esta idea Kant abrió las puertas a un tipo de desarrollo filosófico en el que la subjetividad se autocomprende como libertad creadora autónoma, desatando esa hybris subjetivista que compromete — como vio Jacobi-, no solo el orden los valores consolidados la certeza de la realidad propia del sentido común» (cf. D. Sánchez Meca, «De Goethe a Nietzsche: clasicismo, romanticismo, dionisismo», cit., p. 54). 
poral de algo formado en un proceso natural infinito, salvando así la posibilidad epistemológica de pensar la multiplicidad inherente a todos los fenómenos, la simultaneidad de sus fuerzas concurrentes y, en definitiva, la generación de toda unidad natural en el flujo incesante de la vida sensible.

En este sentido, la importancia de Goethe radica en que proporcionará a Nietzsche algunas de las herramientas cruciales para articular una temprana crítica a la concepción mecanicista de la naturaleza de signo newtoniano, a su reduccionismo y a su metodología analítico-disociadora. Desde aquella enriquecedora mirada goetheana, la naturaleza no era ya un conjunto de elementos aislados y particulares que podían ser sometidos pasivamente por un omnipotente sujeto cognoscente, sino un todo que se expresaba en sus partes y que contenía su estructura más propia en su dinámica, en su incesante devenir. Y al clausurar con ello el principio de autorreflexión subjetivo como productor de formas y dominador del mundo a través de ellas, el yo que participaba de esa productividad creadora se plasmaba dinámicamente como formación (Bildung), es decir, como forma que participaba del devenir metamórfico del mundo natural. Sobre este punto anotaba el doctorando:

En todo viviente no captamos sino formas. Lo que eternamente deviene es la vida. La naturaleza de nuestro entendimiento nos permite captar formas; nuestro entendimiento no es lo bastante fino como para percibir la continua transformación: a lo que puede conocer, lo llama forma [...] Un concepto semejante al de la forma es el concepto de individuo. Se llama así a los organismos en cuanto unidades, en cuanto centros de fines. Pero para nuestro entendimiento no hay más que unidades. Todo individuo comporta en sí mismo una infinidad de individuos vivientes (OC I, 261).

En otras palabras, el Goethe científico le mostraba que era posible modificar la relación cognoscitiva del hombre con respecto a la naturaleza, porque reafirmaba la idea de una consideración estética de todas las formas existentes en la naturaleza y la cultura como unidades meramente ficticias, estabilizadas por la acción de nuestra facultad cognoscitiva que las seccionaba en la continuidad del devenir. En ese primer magisterio goetheano, que Nietzsche había ampliado, entre otros, con las enriquecedoras lecturas de Friedrich Albert Lange y Kuno Fischer sobre la poetización del concepto, así como el carácter fisiológico del conocimiento y la dimensión inconsciente y creativa de toda representación simbólica, sin duda se ganaba mucho: no había explicación y significado de la cultura desligados de la naturaleza, precisamente porque la falaz disociación entre representación científica y estética revelaba un origen común que obligaba quizá a pensar otra relación hombre-naturaleza.

\section{Goethe como paradigma de la Bildung}

Para el joven Nietzsche de los años basilenses, la noción de Bildung es eminentemente aristocrática y restrictiva. Por Bildung debe entenderse aquella búsqueda y emulación de los grandes ejemplares de la cultura que pueden impulsar, en cuanto modelo ideal, la propia autoformación del individuo, de un modo similar a como lo hicieron los antiguos griegos. Por un lado, pues, dicha noción asume la premisa schopenhaueriana sobre la ejemplaridad del genio, es decir, sobre el carácter paradigmático de aquellos poquísimos individuos fuertes y nobles de nuestra tradición cultural cuyo ethos y pathos aristocráticos servían para com- 
prenderse mejor a sí mismo y elevarse en sentido espiritual y moral. Igual que en la «república de los genios» de la que hablaba Schopenhauer (PHG, 1; HL, 9), la reflexión nietzscheana sobre la Bildung restringía el acceso a la verdadera ejemplaridad, pero radicalizaba ese topos desde nuevos parámetros tardoilustrados de fragmentación y mediocridad individuales en la joven Alemania bismarckiana.

Desde esta concepción elitista de la Bildung, la figura de Goethe — del último Goethe, sobre todo el de las Conversaciones con Eckermann- adquirirá un protagonismo muy concreto. Tanto en Sobre el futuro de nuestros centros de formación como en las tres primeras Intempestivas, Goethe se convierte en el modelo por excelencia para afrontar el propio quehacer espiritual sin renunciar por ello a la dimensión artística que subyace siempre a toda actividad práctica. Sin ir más lejos, la profunda preocupación de Goethe por la Bildung, concebida en su Meister como proceso armónico que conduce a la madurez integral de la persona tanto en su vertiente individual como social, conectaba directamente con la apertura epistemológica de su reflexión morfológica en el ámbito de las ciencias naturales. Del mismo modo que en la evolución interior orgánica de los seres vivos incidían factores exógenos que definían su metamorfosis de un modo no determinista y mecánico, también la formación del ser humano concreto podía comprenderse, análogamente, desde estos parámetros en cierto modo morfológicos. Con ello, los vasos comunicantes entre ciencia y arte, también entre vida y literatura, mostraban una potencialidad sumamente creativa que no podía pasar desapercibida a Nietzsche ${ }^{8}$, puesto que la comprensión goetheana de la historia a partir de la naturaleza mostraba que la formación del yo se articulaba en un movimiento doble: por un lado, formación como sufrimiento y tragicidad de la perdida de sí, como nacimiento y muerte continuos $^{9}$; pero, por el otro, como liberación de las estructuras rígidas que oprimen y limitan el yo, permitiéndolo acceder una y otra vez a un ser nuevo, como parte integrante de un proceso configurador de sobrepasamiento continuo de sí. Ambos momentos, expresados en la asunción goetheana de un impulso de formación poética (poetischer Bildungstrieb), reevaluaban con ello una noción más originaria de poiesis, en cuyo núcleo performativo se jugaba una comprensión abierta de nuestro conocimiento como praxis elevada sobre el mundo exterior, como actividad configuradora que solo se realiza en virtud de un rodeo imprescindible a través del mundo. En una observación tardía Goethe dirá al respecto:

8. En un fragmento poco conocido de esta época «intempestiva» (invierno 1872/1873), al hilo de la lectura de los Materialien zur Farbenlehre, Nietzsche había anotado la siguiente cita: «Exigencias para una obra de arte científica: no se debería excluir de la actividad científica ninguna de las fuerzas humanas. Los abismos del presentimiento, una segura visión del presente, profundidad matemática, exactitud física, altura de la razón, agudeza del intelecto, fantasía móvil y anhelante, alegría amorosa por lo sensible, de nada se puede prescindir para atrapar de una manera viva y fecunda el instante, y solo así puede nacer una obra de arte, cualquiera que sea también su contenido» (FP I, 29 [2]). Vemos reflejado aquí una variación del conocido ideal goetheano según el cual la naturaleza y el arte constituyen un todo armónico.

9. «De la naturaleza. Ella representa un espectáculo: si ella misma lo ve, no lo sabemos; y ciertamente lo representa para nosotros, los que estamos en un rincón. - Su espectáculo es siempre nuevo, porque crea siempre nuevos espectadores. La vida es su más bella invención, y la muerte es su artificio para tener mucha vida. Goethe» (FP I, 29 [3]). 
Me pareció sospechosa desde hace mucho tiempo la grande e importante tarea inherente al conócete a ti mismo, me pareció el ardid de sacerdotes unidos en secreto, que confunden a los hombres a través de exigencias imposibles de conseguir y quieren llevar de la actividad frente al mundo exterior a una falsa contemplación interior. El hombre solo se conoce a sí mismo en cuanto conoce el mundo, que descubre solo en sí, y a su vez se descubre a sí mismo solo en el mundo ${ }^{10}$.

Igual que el genio de Weimar, también el joven Nietzsche asumirá la actitud hermenéutica según la cual las ciencias en conjunto, y la historia en particular, solo tendrían sentido en la medida en que perfeccionan algún tipo de actividad que produce efectos vivificantes para quien la ejerza. A este respecto, el dictum goetheano con que abrirá la Segunda Intempestiva condensa ${ }^{11}$, de manera magistral, la ejemplaridad del hombre de acción cuyo criterio de valoración sobre cualquier conocimiento representa la capacidad que ofrece para estimular la vida a superarse a sí misma: «Por lo demás, detesto todo lo que no hace más que instruirme sin aumentar mi actividad o vivificarla inmediatamente» (HL, prólogo, p. 695). Al integrar la voluntad de saber en el arte de la vida, Nietzsche reactualizaba con ello el paradigma del hombre de acción goetheano, cuyo ethos había intentado compensar, con mayor fidelidad y reflexividad hacia la vida, el olvido de una dimensión trágica, sin duda ambigua, irónica y contingente, en la Bildung del yo moderno. El magisterio se mostraba decisivo, porque al resistirse a una comprensión optimista del mundo a partir de la historia, el joven filósofo reactivaba con nuevos argumentos la crítica a ese principio de autorreflexión subjetivo que había pretendido producir las formas y dominar el mundo a través de ellas.

\section{Goethe como referente en la búsqueda de una Kultur alemana}

Que la reflexión filosófico-cultural que se jugaba en las obras de juventud nietzscheanas giró en torno a la posibilidad de reefectuar, en la época moderna, una unidad viviente de la cultura alemana como instancia superior de armonización, eso no debería ser un secreto. De acuerdo con la comprensión del joven Nietzsche, la cultura no debía ser entendida como civilización, tampoco como esencia o sustancia de una nación o un pueblo, sino como unidad de estilo orgánica, viviente, esto es, la cultura como physis, como vida que se traducía en los estados corporales creativos, tal como rezaba la conocida definición de la Primera Intempestiva: «La cultura es ante todo la unidad del estilo artístico de todas las manifestaciones de la vida de un pueblo» (DS, 1, p. 643) ${ }^{12}$.

10. Cf. J. W. Goethe, Sämtliche Werke nach Epochen seines Schaffens, Münchner Ausgabe [MA] vol. 12: Naturwissenschaftliche Hefte. Morphologische Hefte, München/Wien: Hanser, 1989, p. 306, cit. por R. Safranski, Goethe. La vida como obra de arte, Barcelona: Tusquets, 2015, p. 489.

11. Sobre la centralidad de Goethe en la Segunda Intempestiva, cf. V. Vivarelli, «Nietzsche, Goethe und der historische Sinn», en Centauren-Geburte, cit., pp. 276-291. También H. Weinrich, «Postludium: Hat Goethes Faust Nietzsches zweite 'Unzeitgemässe Betrachtung' gelesen?», en «Vom Nutzen und Nachteil der Historie für das Leben». Nietzsche und die Erinnerung der Moderne, D. Borchmeyer (ed.), Fráncfort d. M.: Suhrkamp, 1996, pp. 218-234. Sobre la relación de Goethe con la historia, cf. R. Koselleck, «La historia intempestiva de Goethe»: Atlantis. Revista de pensamiento y educación 3 (2014), pp. 69-88.

12. Cf. también FP I, 8 [92]. 
Por otro lado, tampoco debería ser ningún secreto que, para aspirar a una cultura unificada, la estrategia en cierto modo pre-genealógica de Nietzsche consistió en recurrir a la fuente de toda creatividad, al principio originario del que brotaba la fuerza configuradora que producía las obras de arte en tanto que producto culturales. Ese camino hermenéutico, ensayado ya desde Homero y la filología clásica con una mirada menos normativa y más intuitiva sobre las manifestaciones humanas de la Antigüedad, resultaba decisivo para el presente cultural de Alemania, porque reconstruía un modelo de cultura griego como physis, como naturaleza transfigurada, cuya potencialidad teórica no debía ser infravalorada, sobre todo con vistas a la viabilidad del proyecto wagneriano de renovación estético-política. Así, frente a la comprensión positivista de una Antigüedad operativa solo como unidad de sentido recreable con fuentes y monumentos escritos, con una propedéutica hipotecada por la esterilidad de unas herramientas científicas poco o nada autorreflexivas de la filología clásica y la historia, la comprensión estética del joven Nietzsche apuntaba al corazón de las derivas epistemológicas de la ciencia moderna, acaso uno de los mejores síntomas de agotamiento tardoilustrado. De ahí que la tragedia griega adquiriese un lugar privilegiado en su indagación sobre las condiciones de posibilidad de la salud de una cultura, puesto que en ella tenía lugar aquella aquella Entladung colectiva que seguía escapándose a la rígida comprensión racional del observador moderno. Frente a la mirada moralizante del espectador burgués, la tragedia griega se abría ahora, en palabras de Sánchez Meca, como «modelo de obra de arte capaz de obligar al conjunto de la sociedad a asumir su propia forma. No se asista a ella desde la actitud individualista y puramente contemplativa [...], sino que, con su representación, transforma a una colectividad de espectadores en una individualidad superior, instaura una comunidad de afirmación en y por la obra compartida, y obliga a entrar en esa comunidad de la obra para participar en su vitalidad» ${ }^{13}$.

Pues bien, desde este imprescindible marco teórico, la importancia de Goethe será clave para reforzar la estrategia de legitimación del joven filósofo mediante el recurso a una de las grandes autoridades culturales del país. Lo será en un sentido positivo y otro, por así decirlo, ex negativo:

En un sentido positivo, todo el quehacer del genio weimarés será reinterpretado como una lucha incansable en pos de una unidad cultural propia. La heroica tarea de Goethe y Schiller se insertaría, de acuerdo con esta imagen idealizada del joven Nietzsche, dentro de la metafórica de la lucha y el combate culturales, dimensión genuinamente agonal en la que aquellos nobles y solitarios individuos habrían sentado un decisivo precedente en la construcción de «una duradera alianza de amor entre la cultura alemana y la griega» (GT, 20, p. 419). Igual que los participantes en los certámenes homéricos y hesiódicos habían representado unos artistas im Wettkampf ${ }^{14}$, también aquí se consolidaba una analogía con aquellos luchadores

13. Cf. D. Sánchez Meca, «Introducción al volumen I: la evolución del pensamiento de Nietzsche en sus escritos de juventud", en OC I, 30.

14. Tema ampliamente investigado en sus años universitarios, cf. El tratado florentino sobre Homero y Hesíodo, su origen y su certamen, en OC II, 233-290. Nótese, sin embargo, la pobreza que encierra aquí la habitual traducción de Wettkampf por «certamen». El elemento combativo se diluye y, sobre todo, se pierden las dos principales dimensiones semánticas que subyacen a esta categoría que tanto debe a la mirada burckhardtiana: por un lado, la dimensión del juego de fuerte impronta 
comprometidos de la joven cultura alemana que, con su Bildungskampf, habían construido un espacio cultural de enorme productividad en su propio presente ${ }^{15}$. $\mathrm{Al}$ habilitar ese potente imaginario de la cultura alemana -contrapuesta, por ejemplo, a la categoría de «barbarie» en David Strauss-, Nietzsche conectaba ciertamente con la comprensión aristocrática y elitista de la Bildung, pero sobre todo legitimaba la misión histórico-espiritual del proyecto wagneriano, no menos que el autoposicionamiento del compositor alemán en cuanto verdadero continuador y profundizador de la herencia clasicista: «Wagner completa lo que habían comenzado Schiller y Goethe. En el ámbito propiamente alemán» (FP I, 9 [23]). Se trataba, desde luego, de la cuestión fundante de los verdaderos epígonos — tópos griego por excelencia-, es decir, quién ampliaba la cadena de los genuinos forjadores de la cultura alemana, como Lutero, Beethoven, Schiller o Goethe, y quien, por el contrario, la oxidaba sobremanera con una desfondada y filistea imitatio, fruto de una débil personalidad epocal.

Por otro lado, precisamente en virtud de su fidelidad hacia el relato wagneriano, el aspecto negativo que Nietzsche quiso imprimirle al lugar de Goethe para la cultura alemana era una derivada directa de su excesiva dependencia con respecto a la fundamentación teórica del Gesamtkunstwerk y, desde luego, al esquematismo de una metafísica de la música schopenhaueriana que el joven filósofo no había cuestionado con razonamientos deductivos/inductivos propios. No puede sorprender, por tanto, que buena parte de las limitaciones inherentes al proyecto clasicista que Nietzsche postuló en tantos fragmentos preparatorios se encontraran prefiguradas en el Beethoven wagneriano de $1870^{16}$, a partir de cuya intensa lectura Nietzsche había extraído y ampliado numerosos motivos del Briefwechsel zwischen Schiller y Goethe que resultarían esenciales para cartografiar la relación entre música y lenguaje, como la diferencia entre epos y drama (FP I, 5 [46, 48, 49], 9 [82, 84]), la discusión sobre el símbolo y el concepto (FP I, 9 [54, 83, 77, 99, 147]), sobre ritmo y verso (FP I, 9 [77]) o sobre lo «patológico» (FP I, 9 [90, 92]). Si hubiera que llevar todos estos elementos de la crítica nietzscheana a un denominador común, podríamos hablar de una falta de música en las producciones dramáticas del clasicismo weimarés, de cuya carencia se infería, mutandis mutandi, su incapacidad para lo trágico ${ }^{17}$.

El argumentum ex negativo sobre Goethe se cifraba, en otras palabras, en el hecho de haber proyectado una Antigüedad idealizada a todas luces insuficiente e

heraclítea, es decir, el elemento lúdico de quien participa en y que apuesta por el agon —en alemán, el prefijo Wett-remite a wetten, que significa «apostar»-; por el otro, la lucha propiamente dicha, der Kampf o das Kämpfen, así como su sinónimo das Ringen, que posibilita a su vez la construcción das Ringkampf, es decir, el pale griego.

15. Cf. FP I, 16 [4], 19 [225, 270, 274]. Recordemos también las ardientes palabras pronunciadas en enero de 1872, con ocasión de la primera conferencia de Sobre el futuro de nuestros centros de formación: «Los que luchan, es decir, los llenos de esperanza, cuya expresión más noble y sublime, nuestro gran Schiller, la tenemos ante nuestros ojos como nos los muestra Goethe en su Epílogo a la Campana» (BA, introducción, p. 485), cuyo verso «a la resistencia del mundo obtuso vence» es un Leitmotiv muy querido por el joven Nietzsche, cf. BA IV, p. 527, DS, 4, p. 658.

16. Recientemente publicado en castellano, cf. R. Wagner, Beethoven, seguido de La dirección de orquesta, ed. de B. Matamoro, Madrid: Fórcola, 2016. Por lo demás, son numerosos los fragmentos que recogen ideas directas de su lectura, cf. FP I, 7 [152], 8 [4, 47, 64, 96], 11 [1], 12 [1], 14 [3].

17. Sobre este tema, cf. A. Venturelli, «Das Klassische als Vollendung des Sentimentalischen. Der junge Nietzsche als Leser des Briefwechsels zwischen Schiller und Goethe»: Nietzsche-Studien 18 (1989), 182-202. 
ingenua. Al construir una idealidad de sentido que tomaba la jovialidad, la serenidad y la mesura griegos como únicos impulsos fundantes de su cultura, la imagen clasicista y neohumanista de aquella Grecia goetheana, deudora del magisterio generacional de Winckelmann, resultaba ciertamente incompleta, porque no incorporaba aquel sustrato violento, arcaico, no olímpico, que señalaba hacia Asia; porque omitía la importancia de lo cultual y mistérico, de lo orgiástico y extático, o sea, desconocía aquel reverso de la imagen épica y apolínea que su producción artística había privilegiado. Al concentrar sus esfuerzos poéticos dentro de los parámetros de «la epopeya dramatizada, en cuyo ámbito artístico apolíneo el efecto trágico es, obviamente inalcanzable» (GT, 12, p. 384), Goethe se había detenido frente a la experiencia trágica, al borde mismo del abismo, incapaz de darle muerte a una bella Nausícaa que se convertía, por ello, en símbolo encarnado de la incapacidad más profunda del genio weimarés. A Schiller llegará a confesarle en la famosa carta del 9 de diciembre (que Nietzsche estudió a fondo): «Es cierto que no me conozco a mí mismo lo suficiente para saber sí sería capaz de escribir una verdadera tragedia, pero la mera idea de la empresa ya me aterra, y estoy casi convencido de que el solo hecho de intentarlo podría destruirme» ${ }^{18}$.

Con esta última reflexión sobre la supuesta incapacidad goetheana para lo trágico llegamos, si bien por otros caminos, al mismo corazón del Fausto, obra inconmensurable que, si atendemos a su subtítulo, Goethe sí quiso definir como eine Tragödie $^{19}$. Sea como fuere, en lo que sigue nos aproximaremos, con una lectura más intertextual, a la estrategia que el joven Nietzsche seguirá en El nacimiento de la tragedia para integrar y reactualizar el imaginario fáustico en el contexto de su indagación sobre el origen de la tragedia griega y asignarle, al mismo tiempo, una original función filosófico-cultural. Nos preguntaremos, en este sentido, si en su particular apropiación creativa de numerosas texturas de lo fáustico, Nietzsche asume las tres dimensiones de lo goetheano que acabamos de presentar.

El primer momento fáustico que quisiera comentar surge de la estilizada contraposición entre el Nietzsche maduro en su «Ensayo de autocrítica» y el posicionamiento de juventud en el capítulo 18 de su opera prima ${ }^{20}$. Se recordará que el núcleo de la crítica en dicho capítulo se centraba en la figura optimista del ser

18. Cf. J. W. Goethe y F. Schiller, Der Briefwechsel. Eine Auswabl, ed. de R. Safranski, Frankfurt a. M.: Fischer, 2011, p. 216.

19. Frente a la inconmensurabilidad bibliográfica de esta enorme obra universal, me limitaré a señalar aquellas obras introductorias de innegable rigor que me han servido para preparar este trabajo, sobre todo J. Schmidt, Goethes Faust. Erster und Zweiter Teil. Grundlagen - Werk - Wirkung, Múnich: C. H. Beck, ${ }^{3} 2011$. Para el público hispanohablante resultan útiles los trabajos de Jordi Jané («El Fausto en su contexto ético») y Feliciano Pérez Varas («La configuración de un mito: el Fausto»), ambos contenidos en la recomendable obra coral Encuentros con Goethe, L. A. Acosta et al. (eds.), Madrid: Trotta, 2011.

20. Herramientas imprescindibles para un trabajo histórico-filológico e histórico-crítico sobre esta compleja obra siguen siendo, para los primeros doce capítulos, B. v. Reibnitz, Ein Kommentar $z u$ Friedrich Nietzsche 'Die Geburt der Tragödie aus dem Geiste der Musik' (Kapitel 1-12), Stuttgart/ Weimar: J. B. Metzler, 1992, así como el reciente Nietzsche-Kommentar firmado por J. Schmidt. 
humano teórico, alguien que, por estar preso de la red de la llamada «cultura alejandrina», encarnaba como pocos la frustración provocada por la insuficiencia, la inoperancia y la vaciedad de las ciencias modernas. Tales dimensiones de la subjetividad moderna, aunque todavía recientes, habían sido condensadas literariamente en el personaje de Fausto, contrapunto de un ser helénico que, de acuerdo con la nietzscheana comprensión fisiológica de la cultura griega, jamás habría permitido semejante alejamiento intelectual en detrimento de la vida misma: "Qué incomprensible tendría que parecerle a un griego el auténtico Fausto, el en sí comprensible ser humano cultural moderno, el Fausto que se lanza insatisfecho a través de todas las facultades universitarias, entregado, desde su pulsión por el saber, a la magia y al demonio» (GT, 18, p. 408).

Nietzsche asocia la imagen moderna del ser humano teórico a la búsqueda desesperada de Fausto por comprender el mundo y la naturaleza desde el refugio de cualquier tipo de saber o ciencia que pueda saciar su desesperada aspiración cognoscitiva, su apasionado Wissensdrang. En cierto modo, Goethe había plasmado magistralmente la secularización de la curiositas agustiniana en la figura del pobre Doktor, cuya existencia erudita se alimentaba de la todopoderosa melancolía del genio moderno, tal como había resurgido programáticamente en el Sturm und Drang bajo la sombra alargada de Shakespeare. Igual que el joven Werther se había lamentado de la esterilidad productiva de los hombres presuntamente cultivados — «Wir Gebildeten - zu Nichts Verbildeten»-, Fausto encarnaba una pluralidad insaciable de pulsiones de lo absoluto, las cuales lo alienaban del mundo que pretendía comprender desde su yermo rincón:

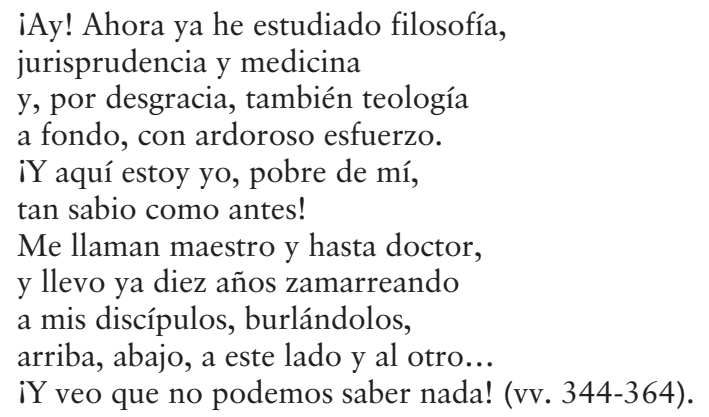

Sin embargo, al reactualizar en el capítulo 18 este conocido lugar común de la tradición fáustica, Nietzsche amplia con nuevos argumentos la incapacidad para actuar del hombre del conocimiento moderno, ese hijo privilegiado de la escuela del socratismo que ha creído corregir los procesos pulsionales e inconscientes de la creación humana por planes conscientes e intenciones críticas guiadas por la razón y el entendimiento. Frente al irónico optimismo de esa cultura socrática, la propuesta nietzscheana consistirá en una «cultura que yo me atrevo a designar como trágica: cuya característica más importante es que el lugar de la ciencia como meta suprema lo ocupa la sabiduría, la cual, sin caer en los engaños de las seductoras ciencias, se dirige con mirada inalterada hacia la imagen total del mundo» (GT, 18, p. 411). Y precisamente aquí, después de este pasaje exacto, entra en escena aquella misma pregunta que el Nietzsche maduro volverá a transcribir, quince años después, en su «Ensayo de autocrítica»: 
¿no debería ser necesario que el ser humano trágico de esa cultura, en su autoeducación para la seriedad y para el horror, tuviese que desear un arte nuevo, el arte del consuelo metafísico, la tragedia, como la Helena que le es inherente, y tuviese que exclamar con Fausto:

Y no debo yo, con violencia colmada de nostalgia,

traer a la vida esa figura de máxima singularidad? («Ensayo de autocrítica», 7, p. 335)

De lo que aquí se trata, por tanto, es intentar dilucidar por qué Nietzsche ofrece dos respuestas tan distintas a la misma pregunta de índole fáustica. Para ello es preciso recordar que estos dos últimos versos de la segunda parte del Fausto (vv. 7438 ss.) nos remiten al descenso de Fausto hacia el mundo no-configurado de la vida mitológica, caótica y desenfrenada, originaria y pulsional, tal como se expone en la Klassische Walpurgisnacht ${ }^{21}$. La búsqueda fáustica de Helena desde las profundidades naturales de la vida es en cierto modo platónica, porque el posterior ascenso hacia el mundo de las formas bellas recreará un deseo erótico, sin duda sublimado, que configura una idea de lo bello cuya perfección adquiere rango de universalidad. Por otro lado, en cuanto encuentro nostálgico con la Antigüedad, la estilizada figura de Helena asume en Goethe también importantes rasgos compensatorios, ya que simboliza la armonía entre naturaleza y cultura: representa la culminación de una Bildung ahora concluida. En cuanto encarnación del Renacimiento y su continuidad en el clasicismo weimarés, la sonrisa eterna de Helena dibujada por Goethe había demostrado, en última instancia, que la posibilidad de un renacer creativo y creador, al menos desde parámetros no cristianos o románticos, pasaba por una reflexión más autoconsciente sobre la esfera originaria de lo poético, al punto cero interior de la fuerza creadora.

Para el joven Nietzsche, en cambio, la figura de la Helena fáustica sirve para explicar, en el marco de la contraposición entre lo apolíneo y lo dionisíaco, el modo en que los seres humanos logramos, a través de las creaciones del arte, ocultar la pena y el dolor universales. Desde luego, el toque schopenhaueriano resulta aquí decisivo para redefinir la función de Helena en su metafísica estética. Pues si lo apolíneo sirve a lo dionisíaco para que la desmesura de lo dionisíaco se convierta en una experiencia sublimada, detrás de la seductora sonrisa de Helena, detrás de la idea de lo bello, se ocultará siempre una transfiguración de lo terrible. La sonrisa no es sino aquella transfiguración lograda a través de la representación, productora de formas artísticas serenas y mesuradas que mitigan y disuelven el horror, volviendo soportable lo que es constitutivamente feo y doloroso. Lo bello sería, en consecuencia, una sensación de placer, un velo estético que nos oculta las verdaderas intenciones que tiene la voluntad en un fenómeno, una bella apariencia, un schöner Schein schilleriano. En un fragmento preparatorio dirá incluso: «Un sueño feliz sobre el rostro de un ser, cuyos rasgos ahora sonríen con esperanza. Con este sueño ve Fausto a 'Helena' en cada mujer» (FP I, 7 [28]).

Mientras que el joven Nietzsche respondía a la pregunta arriba planteada de manera afirmativa, el Nietzsche maduro contestará, por el contrario, con una triple negativa:

«¿No debería ser necesario?»... iNo, tres veces no!, jóvenes románticos: ino debería ser necesario! Pero es muy probable que eso acabe así, que vosotros acabéis así, es de-

21. Para un análisis de este tercer acto, cf. Schmidt, Goethes Faust, op. cit., pp. 234-264. 
cir, «consolados», como está escrito, pese a toda la autoeducación para la seriedad y para el horror, «metafísicamente consolados», en suma, como acaban los románticos, cristianamente... (GT, «Ensayo de autocrítica», 7, p. 335).

Ahora, en plena madurez de su pensamiento, Nietzsche constata que el ser humano trágico que quiso reconocer en aquel audaz matadragones moderno -Sigfrido- se había convertido en una figura enferma y decadente, cuestionando de lleno la tesis juvenil de que las creaciones del arte, en cuanto actividad propiamente metafísica del ser humano, eran el fin supremo del placer de la voluntad. Al justificar la existencia del mundo como fenómeno estético ${ }^{22}$, al reducir el mundo moral al mundo de la apariencia, la seductora sonrisa de Helena, en cuanto «belleza en sí», representaba ahora una ficción idealista de la imaginación, cuya capacidad redentora escondía en realidad una sintomatología más profunda, inseparable de un diagnóstico nihilista que revelaba las carencias vitales del ser humano al proyectar un sentido y un valor en trasmundos o trascendencias cualesquiera. La reducción nietzscheana de lo estético a lo fisiológico buscaba ahora fundamentar la vida en su autoproducción creadora, deificando el mundo real falsificándolo. Por eso la conquista reflexiva del último Nietzsche enlazaba mejor con la función hermenéutica de la belleza en el Fausto, en cuanto despedida de la vida con gozo como única forma genuinamente humana de renunciar a la omnipotencia. En esa tarea goetheana de la belleza, tal como señala José Luis Villacañas, «se nos ofrece una omnipotencia formal que se niega a sí misma como realidad, la de la visión extática en la obra de arte que es consciente de su dimensión alucinatoria, ficcional, irreal» ${ }^{23}$.

En definitiva, Nietzsche seguía ahora a Goethe en su afirmación de la vida desbordante que hace existir lo bello y lo feo, lo bueno y lo malo, porque su fuerza está más allá del bien y del mal. La afirmación de la vida en el más acá desde parámetros no románticos mostraba que, frente a lo que había defendido en su juventud, el carácter consolador de las obras de arte wagnerianas acercaban al compositor alemán más bien a los dominios de Mefisto. Ambos, al reafirmar la necesidad de un mundo de la apariencia, un mundo también de engaño y de autoengaño, se convertían en magos e ilusionistas, histriónicos artistas de la escenificación, irónicos comediantes que colaboraban productivamente en la profundización del nihilismo europeo.

El segundo momento fáustico nos conduce a la segunda parte del capítulo 9. Recordemos que en este capítulo el filósofo estudiará el modo en que los mitos trágicos de Edipo —en su versión sofoclea-y de Prometeo —en su versión esquílea- pueden ser comprendidos a partir de la dualidad estructural de lo apolíneo y lo dionisíaco. Quisiera centrarme en la reflexión acerca del titán Prometeo, de clara filiación goetheana, y ampliarla seguidamente con ayuda de la densidad intertextual de otros momentos del Fausto codificados en la argumentación nietzscheana.

No es baladí recordar aquí que la concepción del mito en el joven Nietzsche se inscribe ciertamente en la tradición romántica de filósofos como, pongamos, el menor de los Schlegel o Friedrich Schelling, y de filólogos como Creuzer,

22. Sobre este tema, cf. L. E. de Santiago Guervós, «Nietzsche y la justificación estética de la existencia. El placer de lo trágico», en J. Conill-Sancho y D. Sánchez Meca (eds.), Guía Comares de Nietzsche, Granada: Comares, 2014, pp. 25-46.

23. Cf. J. L. Villacañas, «Freud sobre Fausto: sustituciones de la omnipotencia»: Arbor: ciencia, pensamiento y cultura, CLXXXIII/723 (2007), pp. 123-133, aquí p. 130. 
Welcker o Heyne, autores todos ellos que consideraban el mito no tanto como objeto histórico a investigar, sino como elemento fundante de la cultura. Frente a la concepción historicista de mito, la opera prima del profesor de Basilea apuntaba hacia una comprensión más ahistórica, en la que pudiese ensayarse una vía de recuperación, para la época moderna, del poder generador de intuiciones, de mitos y de valores culturales más allá de las meras operaciones instrumentales y analíticas de la razón: «El mito quiere que lo sintamos intuitivamente como un ejemplo único de una universalidad y una verdad que miran fijamente hacia lo infinito» (GT, 17, p. 406). O bien: «el destino de todo mito es irse arrastrando poco a poco hacia la estrechez de una realidad presuntamente histórica y ser tratado por cualquier época posterior como un factum ocurrido una vez, con pretensiones históricas» (GT, 10, p. 376).

Lo significativo de este conocido posicionamiento teórico es que, en el capítulo 9, recurrirá, para ejemplificarse, a un imaginario que no pertenece estrictamente ni a la Frühromantik alemana ni, por otro lado, al clasicismo weimarés, sino a aquel periodo cultural que es su condición de posibilidad, a saber: el Sturm und Drang. El recurso nietzscheano al rebelde Prometeo, símbolo par excellence del individuo creador, del artista genial forjador de la cultura, conectaba con aquel primer momento reflexivo de la joven cultura alemana en que la poesía, exactamente igual que el mito, había creado un sentido que antes no había existido como tal ${ }^{24}$. Precisamente porque la figura hímnica plasmada por Goethe entre 1772 y 1774 recuperaba, siguiendo a Shaftesbury vía Herder, el sentido perfomativo de poiêin aplicado al poeta, en cuanto creador o hacedor que solo reconoce y acepta sobre sí una única instancia normativa - su propia capacidad moldeadora, su bildende Kraft - la ordenación del caos del mundo realizada por el lenguaje de la imaginación humana encontraba fascinantes analogías con el mito. En ambos momentos creativos y creadores se expresaba la vitalidad misma de la naturaleza, no menos que su infinita variedad y riqueza multiforme, pero como condensación simbólica y espontánea, pues ambos momentos logificadores no erosionaban la singularidad del mundo en su acontecer, sino que expresaban la pulsionalidad que subyacía a la vida del mundo. Recordemos los conocidos versos que tanto interesan a Nietzsche:

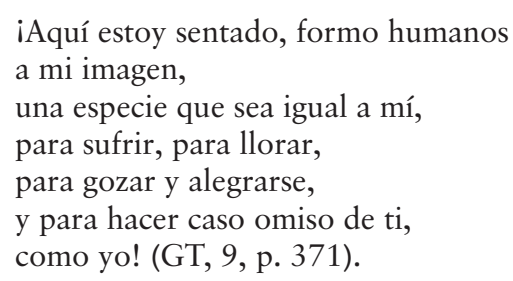

Recogiendo esta densidad de asociaciones mitopoiéticas, la aportación teórica del joven Nietzsche consiste en explicar, en primer lugar, la fuerza creadora del genio desde su capacidad efectiva de desligarse del principio de imitación de una

24. Sobre este tema, cf. A. Rudolph, «Proteusfiguren esoterischer Ästhetik bei Wieland, Hamann und Goethe», en Aufklärung und Esoterik: Rezeption - Integration - Konfrontation, M. NeugebauerWölk (ed.), Tübingen: M. Niemeyer, 2009, pp. 395-438. También el trabajo de C. García Gual, «Goethe frente a Prometeo»: Estudios clásicos 88 (1984), pp. 453-458. 
realidad previamente dada. Ese poder titánico, que se patentiza en el tránsito de la mimesis a la poiesis, surge de la firme convicción nietzscheana de que si el arte no puede reducirse a imitar la vida - puesto que ha de ser él mismo expresión de la vida individual - la producción de formas del artista dionisíaco implicará un actividad que conciba la naturaleza como fuerza simultáneamente creadora y destructora, como devenir de un mundo cuyo atributo esencial es ser «una contradicción» y un "sufrimiento originario", como en el caso de Prometeo. Estas dos dimensiones de la máscara prometeica, la primera, como artista apolíneo productor de formas mesuradas, como la justicia armónica, la segunda, como máscara del sufriente que busca sobrepasar el hechizo de la individuación y tender hacia lo universal, son resueltas dialécticamente al final del capítulo apelando a la «esencia doble» de toda máscara, «su naturaleza a la vez dionisíaca y apolínea, se podría expresar usando una fórmula conceptual de esta manera: 'Todo lo existente es justo e injusto, y en ambos casos está igualmente justificado'. iHe aquí tu mundo! iHe aquí lo que significa un mundo! — (GT, 9, p. 373).

Esta fórmula conceptual, que reactualiza la comprensión heraclítea de la justicia (Diels/Kranz, fr. 22 B 102) bajo el horizonte moderno de los famosos versos de Fausto I (vv. 409 s.), reafirma la filiación nietzscheana respecto de aquella goetheana comprensión de la naturaleza como physis transfigurada, siempre indiferente respecto del destino del hombre, en que la existencia humana no constituye ningún factor de privilegio en el flujo de la vida incesante. De este modo, la dimensión supramoral (y anticristiana) que anuda el Prometeo goetheano con la reinterpretación del Prometeo nietzscheano en este noveno capítulo reflejan nuevamente la convicción compartida según la cual la vida desbordante que hace existir lo bello y lo feo, lo bueno y lo malo, opera siempre desde parámetros que van más allá del bien y del mal. Prescindir de una justificación moral del mundo mediante la reevaluación del paradigma estético significa, en cierto modo, asumir las consecuencias antropológicas de la secularización del principio metafísico de lo divino, donde, al trasladar la idea de lo bueno a la pura inmanencia, al orden natural en el mundo, el reto intramundano del hombre de acción consiste en fundamentar cómo lo malo puede llegar a convertirse en condición de lo bueno. $\mathrm{El}$ arte hace soportable la vida en la medida en que, mediante su transfiguración como placer de la belleza, el sufrimiento y la contradicción pueden producir un placer superior desde es el que es posible la afirmación de la vida como tal.

El tercer entramado textual que quisiera comentar se encuentra tanto en el primer como en el octavo capítulo. En estos dos pasajes, se asocia la fuerza dionisíaca de la música con la bella imagen fáustica de «un mar eterno, una trama cambiante, un ardiente vivir» (Ein ewiges Meer, Ein wechselnd Weben, Ein glühend Leben). Esta potente imagen, de enorme densidad metaforológica, nos retrotrae a la primera escena nocturna del Fausto, cuando la desperatio de nuestro melancólico protagonista le lleva a invocar al espíritu de la tierra (Erdgeist), que le explica sin ambages cuál es su quehacer el mundo como correa de transmisión intuitiva con el «macrocosmos», permitiendo así la comunicación con la esencia más íntima de la naturaleza:

En el oleaje de la vida, en la tormenta de la acción, 


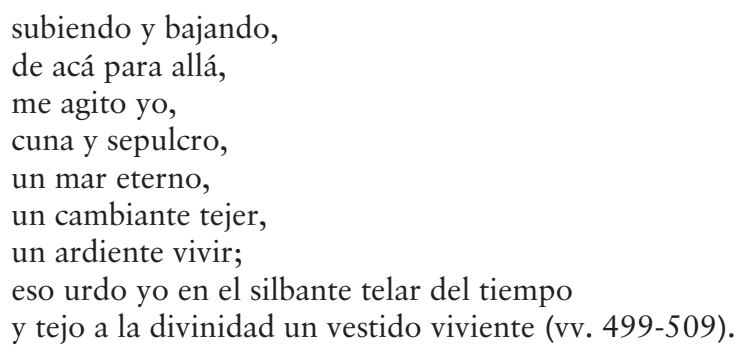

Al contextualizar el surgimiento de la figura del Erdgeist desde los orígenes juveniles de la filosofía de la naturaleza goetheana, que asume, además de Spinoza, elementos de la tradición estoica, neoplatónica o hermética, difícilmente nos equivoquemos al afirmar que su monólogo frente a Fausto condensa poéticamente aquella primera concepción panteísta asimilada por el apasionado Stürmer en sus decisivos años de Estrasburgo ${ }^{25}$. Por otro lado, la recuperación del imaginario de la natura textor —el verbo weben significa «tejer», «urdir», «hilvanar»— apuntaba precisamente hacia esa dirección panteísta. El vestido viviente, la vestidura de la divinidad representa la naturaleza pasiva, la naturaleza que ya ha llegado a ser (natura naturata), la cual es confeccionada y moldeada, a su vez, por el principio configurador interno y activo de la vida (natura naturans), es decir, la naturaleza creadora. De este modo, el espíritu de la tierra reproducía fielmente las intenciones spinozistas del joven Goethe: el hombre cumple su destino cuando, como natura naturata, participa en la natura naturans. Dios es su naturaleza en toda su riqueza y su fuerza creadora. Y el hombre ha de descubrir, conservar y activar esta fuerza creadora, que también vive en él. De ahí que la actividad, la acción (Handlung) sea el verdadero culto divino a la naturaleza.

Desde este fondo especulativo, lo que hará el joven Nietzsche será establecer una analogía entre la comprensión activa del espíritu fáustico y la capacidad del arte dionisíaco -esto es, de la música entendida schopenhauerianamente como lenguaje inmediato de la voluntad- de ser también una pulsión artística de la propia naturaleza. Igual que el originario sustrato vital que impulsa al Erdgeist a asumir su función creadora en el theatrum mundi secularizado por Goethe junto a otros actores como Dios, los ángeles, el macrocosmos y, desde luego, el mismísimo demonio- permite la anhelada comunicación de Fausto con la esencia más íntima de la naturaleza, también la música dionisíaca, si bien como expresión metafísica de la esencia del mundo, representa un extraordinario torrente de fuerzas naturales que todavía no ha sido condensado poéticamente en el medio de la imagen. Por otro lado, la asunción parcial del panteísmo goetheano no solo se revela en el hecho de que «bajo la magia de lo dionisíaco» sea posible entretejer de nuevo «la alianza de persona a persona», esto es, disolver el doloroso hechizo de la individuación en virtud de la experiencia comunitaria y transformadora que produce la celebración trágica. Dicho sustrato se vuelve todavía más palpable en

25. Localizada ya en su Urfaust, la escena del espíritu reflejaba un sedimento decisivo en la propia formación goetheana, al integrar una visión sensible y vivificante de la naturaleza como polaridad que lo comprendía 'todo y uno', inseparable, por tanto, de aquella lectura de Spinoza y la provocativa asunción de su Deus sive natura. Cf. J. Schmidt, op. cit., pp. 85 ss. 
el hecho de que sea precisamente «la naturaleza alienada, hostil o subyugada que celebra de nuevo su fiesta de reconciliación con su hijo perdido, el ser humano» (GT, 1, p. 341). Con ello emerge, de acuerdo con Nietzsche, una de las grandes enseñanzas estéticas del artista total griego con respecto a su mal entendida imitación de la naturaleza: en tanto que imitador, el hombre puede ser concebido simultáneamente como artista dionisíaco de la embriaguez y artista apolíneo de los sueños, cuya duplicidad brotaría siempre de la misma naturaleza. Pero en la medida que la dualidad originaria de dicha imitación es entendida más en términos spinozistas (imitación de la natura naturans) que en términos winckelmannianos (imitación de la natura naturata), está conecta con el dinamismo y paganismo más propio de la concepción de la naturaleza goetheana.

Las últimas texturas fáusticas que quisiera comentar pueden englobarse bajo el rótulo de lo «eternamente femenino", más concretamente, mediante la incorporación nietzscheana del imaginario de las brujas, de Helena y de las llamadas «madres del ser».

En relación al tema de las brujas fáusticas y su llamativa presencia en El nacimiento de la tragedia, un buen punto de partida lo ofrece un conocido pasaje del capítulo 2, en el que podemos leer con ocasión de las festividades babilónicas o romanas:

Casi en todas partes el punto central de esas festividades consistía en un desbordante desenfreno sexual, cuyas olas irrumpían acrecidas por encima de toda institución familiar y de sus estatutos venerables; aquí se desencadenaba precisamente a las bestias más salvajes de la naturaleza, hasta llegar a aquella mezcla abominable de voluptuosidad y crueldad que a mí me ha parecido siempre la auténtica «pócima de las brujas» (GT, 2, p. 343).

La reelaboración creativa, el patchwork de Nietzsche consiste en engarzar aquí la delirante escena VI en la cocina de las brujas (vv. 2336 ss.) con la «voluptuosidad» (Wollust) y la «crueldad» (Grausamkeit) de las mismas, tal como se plasmará más adelante en la escena XXI de la primera «Noche de Walpurgis» (vv. 3835 ss.). Por otro lado, su clara intención de asociar ambos momentos de sensualismo desenfrenado y orgiástico se inscribe dentro de una larga tradición ortodoxa protestante, en cuyo imaginario las analogías entre Dioniso y el tópos de Walpurgis no eran infrecuentes: los elementos compartidos de la danza, el exceso, la desnudez y el vino, la animalización y la satirización, los rituales y la primavera, todo ello constituye una suerte de iconografía de lo obsceno, en cuya recurrente plasmación se había traslucido ciertamente el problema mismo de la sexualidad durante toda la época cristiana. Todas aquellas dimensiones psíquicas más ocultas y reprimidas del ser humano habían confluido, en ambas proyecciones antropológicas del hombre o mujer salvajes, en una actitud condenatoria hacia cualquier reducción materialista de nuestros deseos a lo meramente corporal, hacia cualquier sumergimiento demoníaco en una Sinnlichkeit más primitiva que no estuviese sublimada por la comprensión moral del mundo cristiano. Y justo aquí radicaba la riqueza hermenéutica de la visita nocturna a las brujas planteada por Mefisto, encarnación de la mera secularización del placer, porque en la medida en que invitaba a Fausto a tomar aquella pócima había señalado la coexistencia de aquellas dos dimensiones ambivalentes del eros: por un lado, como sensibilidad pulsional, impulsiva, como 
desenfreno sexual latente, como violento rapto a Margarita en cuanto dimensión erótica del pueblo llano; por otro lado, como amor noble, como capacidad para la sublimación erótica, en cuya espiritualización ya se había lamentado su desgarrado pecho: Zwei Seelen wohnen, ach! in meiner Brust (v. 1112).

La proyección simbólica Nietzsche en relación a las brujas asume ya este horizonte secularizado, pero insiste más bien en aquel sedimento cultural de la Antigüedad en cierto modo oriental, en aquel momento dionisíaco que se jugaba performativamente en la «transformación mágica» de las tragedias griegas y que permitía al conjunto de la sociedad asumir su propia forma, sin rehuir el dolor, la fealdad o la pura sexualidad, como sí seguía haciendo el espectador moderno con su moralizante juicio estético:

Y así el espectador se encontrará tan consternado ante esta fantástica superabundancia de vida que se preguntará con qué poción mágica en el cuerpo esos seres humanos superbravos pudieron gozar de la vida, de modo que, mirasen donde mirasen, tenían frente a ellos a Helena, imagen ideal «presente en dulce sensualidad» de su propia existencia, que reía (GT, 3, p. 345).

Como se observa, además del clásico tópos de la desenfrenada y «dulce sensualidad» demoníaca (Du siehst, mit diesem Trank im Leibe/Bald Helenen in jedem Weibe), también el imaginario fáustico de la Klassische Walpurgisnacht, perteneciente a la segunda parte del Fausto, obtiene aquí su protagonismo. A diferencia de la trágica resolución con Margarita, el encuentro con la bella Helena representa una compleja figuración de aquel proceso cultural de creación y educación hacia una belleza clásica como naturaleza ideal. La figura de Helena, armonía entre naturaleza y cultura, supone la culminación de una Bildung genuina, de ahí que la búsqueda de Fausto reflejara, por un lado, las aspiraciones más íntimas del programa clasicista y su orientación hacia una cultura estética de la Antigüedad. Sin embargo, por el otro, señalaban el propio destino de Fausto en el reino de lo estético, es decir, la viabilidad de su salvación a través de la comprensión del goce estético, de la comprensión de la belleza de un instante que le llevaba a renunciar a toda aspiración de omnipotencia y de promesa mundana de inmortalidad.

A la luz de esta sugerente trama de asociaciones, no puede sorprender que Nietzsche incorporara a su entramado aquellas decisivas figuras femeninas que, durante el descenso de Fausto, habían simbolizado el reino de lo estético par excellence, a saber: las «madres del ser» (Mütter des Seins). A ellas se referirá en el capítulo $16^{26}$, pero también al final del capítulo 20: «La tragedia se halla en medio de esta superabundancia de vida, sufrimiento y placer, en sublime éxtasis, y escucha un lejano canto melancólico - este habla de las madres del ser, cuyos nombres son: la ilusión, la voluntad y la pena» (GT, 20, p. 421).

26. «Bajo el místico grito de júbilo de Dioniso estalla el hechizo de la individuación y queda abierto el camino hacia las madres del ser, hacia el núcleo más íntimo de las cosas». «En el arte dionisíaco y en su simbolismo trágico la naturaleza misma nos dirige la palabra con su voz verdadera, no cambiada: 'iSed lo que soy! iBajo el cambio incesante de los fenómenos, la madre primordial eternamente creadora, la madre primordial que eternamente apremia hacia la existencia y que eternamente encuentra en este cambio de los fenómenos su propia satisfacción!’»(GT, 16, pp. 399 y 403). Cf. también FP I, 5 [2], 9 [106]. 
¿Cómo entender la reinterpretación nietzscheana de aquel abstracto reino atemporal y elemental de vida desbordante, en el que Fausto descendía hasta el grado cero de la creatividad originaria, hasta el «vacío» (v. 6232), «el todo» y la «nada» (v. 6256)? A mi modo de ver, las madres del ser, tal como son integradas en la dualidad estructural de El nacimiento de la tragedia, son un magnífico ejemplo de cómo la sexualidad opera funciona en Nietzsche como analogía explicativa, como metáfora descriptiva que se nos brinda para que intuyamos mejor una hipótesis metafísico-estética. Como ha investigado Joan B. Llinares, la polaridad sexual del dios-artista Dioniso, cuyos atributos femeninos, su «seno materno", su «matriz» y su «regazo», conviven con una manifiesta caracterización como «juez», «señor» y «héroe genuino», nos ayuda a comprender que, «en el ámbito de la cultura, los artistas, los genios, los hombres verdaderos poderosos sí pueden procrear poemas, sinfonías o cuadros, esto es, obras de arte. La diferencia sexual entre lo femenino y lo masculino posibilita incluso una doble perspectiva sobre el arte, la del artista creador y el receptor. En todo caso permite la vivencia de la maternidad a los varones: su 'seno materno' o su 'matriz espiritual'» ${ }^{27}$.

$\mathrm{Al}$ naturalizar las producciones culturales y postular un mismo origen unificado de todos los procesos de producción de formas (natural, estética, política, social, etc.), la arriesgada explicación genética del joven Nietzsche llegaba, aunque por los senderos dialécticos de su schopenhauerismo, a ese mismo nivel de síntesis binaria en que Goethe había querido identificar la divinidad de la naturaleza matriarcal como fuerza creadora y destructora, en cuanto devenir del mundo. Puesto que la productividad de la naturaleza no era esencialmente distinta de la nuestra, ambas aproximaciones, la una literaria, la otra filosófica, refrendaban ese momento pagano y anticristiano que debía ejercitarse desde una total indiferencia hacia los efectos morales de su vitalismo.

\section{CONCLUSIÓN}

A pesar de haberme dejado en el tintero otros pasajes del Fausto entretejidos en El nacimiento de la tragedia ${ }^{28}$, quisiera haber mostrado que las tres dimensiones de lo goetheano que he desarrollado en la primera parte confluyen, si bien condensadas en el medio poético, en los distintos pasajes seleccionados de la segunda. Esta continuidad, que por lo demás refleja la extraordinaria capacidad hermenéutica que acerca del ser humano puede llegar a tener la literatura clásica, no debe sorprender. Nuestra propuesta de lectura de las texturas de lo fáustico a la luz del triple magisterio de Goethe como científico, como paradigma de la Bildung, como referente en la búsqueda de la Kultur, condensan, más allá de su evidente condición tipológica, tres líneas de fuerza que dan unidad y sentido a una constelación espiritual de enorme productividad y riqueza filosófico-culturales. A modo de conclusión, apuntaremos hacia dos ámbitos de distinto calado que convendría ampliar:

27. Cf. J. B. Llinares, «Nietzsche y la sexualidad», en Estudios sobre la sexualidad en el pensamiento contemporáneo, Pamplona: Navarra Gráfica Ediciones, 2002, pp. 641-689, aquí pp. 657 s.

28. Lista completa en P. Bishop y R. H. Stephenson, Friedrich Nietzsche and Weimar Classicism, cit., pp. $35 \mathrm{~s}$. 
1) Tanto en la cosmovisión fáustica como en la crítica del joven Nietzsche articulada en su opera prima, el animal racional moderno presenta un profundo defecto de construcción. En él, el instinto y la razón no están equilibrados, de ahí que ambos busquen introducir una mejora en la precaria construcción del hombre moderno, haciéndole tomar conciencia de aquellas dimensiones de su subjetividad que, precisamente en virtud de su humanización, habían quedado olvidadas, desatendidas o directamente sepultadas por los desorientadores palimpsestos de la cultura. La conquista de ese momento reflexivo, tanto en Goethe como en Nietzsche, se cifraba en un diagnóstico acuciante sobre el empobrecimiento integral de las fuerzas subjetivas humanas y de la (in)capacidad contemporánea para reconocerlas y vivir con ellas de un modo verdaderamente constructivo y armónico, como praxis elevada sobre el mundo exterior. En ese horizonte secularizado, ambos comprendieron que la viabilidad de una verdadera cultura como physis transfigurada pasaría en todo caso por otro momento de configuración humana, en la que, por un lado, el ser humano adquiriese la conciencia de su propio ser y las posibilidades infinitas de su finitud, y, por el otro, rectificara el pesimismo de la visión corta de lo efímero, en la medida en que plantease la encogida vida de los hombres como desarrollo de las infinitas dimensiones de lo eterno.

2) El horizonte de problematización compartido por el genio weimarés y el joven filósofo sondea, en definitiva, las condiciones de posibilidad adecuadas para delinear, no la realización de la libertad en el reino del arte, sino aquella comprensión estética de nuestra frágil existencia desde una lectura y traducción honestas de lo que debería ser una vida saludable, contingente pero creativa. Nuevamente es el concepto de vida el que parece ser la clave de bóveda, sobre la que deberemos seguir pensando en un futuro. Por el momento, y para terminar, dejaré hablar sobre este complejo asunto al profesor Sánchez Meca, cuyo primer gran trabajo sobre Nietzsche ya intuyó, de forma pionera en nuestro país, lo que quizá se jugaba en el magisterio filosófico de Goethe:

Para Goethe, lo que sirve de nexo y unifica realmente pensamiento no es la actividad racional, sino la vida. El conocimiento objetivo no es, en efecto, otra cosa que un instrumento para resolver necesidades prácticas, y que no puede, como tal, hacer experimentar la conexión del hombre con lo que es, con su principio vital. La vida, en cambio, es el ser como lo abarcante de toda cosa, incluido el hombre [...] En Goethe, son la experiencia estética, el éxtasis y la acción las vías de acceso a lo en sí, es decir, las formas de autoidentificación con la vida que nos constituye y que anima y justifica el universo. En tal sentido, Fausto es el símbolo lírico que él propone de la condición humana, a la que es propia la exigencia de revitalizar una y otra vez conocimiento y existencia en la participación directa en lo originario, rebasando las mediaciones y límites creados por la razón ${ }^{29}$.

29. Cf. D. Sánchez Meca, En torno al superhombre. Nietzsche y la crisis de la modernidad, Barcelona: Anthropos, 1989, pp. 38 s. 